\title{
Biological diversity of fish communities: pattern and process
}

\section{A. E. MAGURRAN ${ }^{* \dagger}$, S. KHACHONPISITSAK ${ }^{*}$, A. B. AHMAD ${ }^{* \dagger}$}

*School of Biology, Scottish Oceans Institute, University of St Andrews, St Andrews, Fife, KY16 8LB, U.K. and Department of Biological Sciences, Faculty of Science and Technology, University Malaysia Terengganu, 21030 Kuala Terengganu, Terengganu, Malaysia

${ }^{\dagger}$ Author to whom correspondence should be addressed.

Tel +44 (0)1334 463506; fax +44 (0)1334 463443; email: aem1@st-andrews.ac.uk

Running head: Biological diversity of fish communities

$20^{\text {th }}$ Jack W. Jones Lecture

Definitive version published as Journal of Fish Biology 2011, Volume 79, pages 1393-1412

DOI: $10.1111 /$ j.1095-8649.2011.03091.x 
For over 150 years ecologists have been striving to explain fundamental patterns of biological diversity, such as the observation that communities invariably consist of common and rare species, and to unravel the processes that underpin these patterns. This task is increasingly urgent given the accelerating loss of biological diversity. Although fishes are the most diverse vertebrate taxon and fish communities occur in a wide range of habitats they have been relatively little studied in the quest to elucidate the processes that shape patterns of biological diversity. Here some of the topics that investigations of fish assemblages can illuminate are highlighted. These include the characteristics of ecological communities and the role that dispersal limitation plays in structuring them, the distinction between core and occasional species, the insights that evaluating abundance in different currencies can bring, and the assessment of community capacity. Questions are identified that future investigations of fish communities might tackle and a case study of a biodiverse ecoregion (Thailand and Peninsula Malaysia) is used to illustrate the need for better links between these ecological questions and effective conservation practice. 


\section{INTRODUCTION}

Fishes are the most diverse of all vertebrate taxa. Nelson (2006) estimates the total number of species of fish as 32500 . Of these some 28400 are considered valid species, where a valid species is one that consists of groups of interbreeding populations that are assumed to be reproductively isolated from other taxa (Nelson, 1999). It is likely that the numbers of valid species sensu Nelson will increase as candidates are more thoroughly documented. On the other hand molecular tools, such as barcoding (Ward et al., 2009; Ardura et al., 2010), can offer different answers to the question of how many fish species there are. For example Zemlak et al. (2009) argued that about a third of the fish species thought to be common to South Africa and Australia are probably two taxa rather than one. But irrespective of how fish species are delineated and counted, it is clear that this is a highly diverse group. To put it in context, there are around 10000 bird species and 5000 mammal species. What is particularly striking, however, is that although freshwaters make up only about $0.01 \%$ of the water on the planet, they support around $40 \%$ of fish species (Nelson, 2006).

Given this variety, fish offer rich opportunities to study a wide range of fundamental questions about biological diversity. Moreover, because rarity and richness go hand in hand, understanding the processes that underpin this diversity is crucial if effective policies for conservation are to be developed. The intertwining of pattern and process in ecology was recognized over 60 years ago (Watt, 1947). New theoretical developments combined with empirical studies now allow a much better understanding of the processes that underpin patterns of biological diversity. This paper focuses on one of the oldest patterns in ecology, which is the observation that communities are composed of species that vary in abundance. How investigations of fish assemblages can lead to new insights into the distribution of commonness and rarity and into the processes that shape these patterns is discussed. The paper concludes by considering how the insights that emerge from this work can aid conservation. The emphasis here is on ecological patterns rather than evolutionary ones but it is recognised that there is a large body of work exploring the origins of biological diversity, and the role of natural and sexual selection, and that fish have been extensively and productively used in this context.

\section{BACKGROUND}

A universal feature of ecological communities is that some species are common, and others typically the majority - are rare. Figures 1 and 2 provide an example of the type of species abundance distributions typically seen in fish communities. The observation that species vary in their proportional abundances with most taxa being rare, was reported by Darwin (1859) and other Victorian naturalists, and was surely obvious to the earliest hunters and gatherers. There is a single known exception to this rule, and this is a case where a bacterium is the sole organism in a gold mine some $2.8 \mathrm{~km}$ below the Earth's surface (Chivian et al., 2008). However, despite the universality of the pattern of commonness and rarity it was not until the $20^{\text {th }}$ century that researchers began to quantify the distribution of species abundances (Motomura, 1932; Raunkaier, 1934; Fisher et al., 1943; Preston, 1948). In essence there are four approaches to quantifying and exploring species abundance distributions: visual and graphical methods; statistical models; tests of biological processes; and neutral models. Although in principle these techniques can be separated into those that describe patterns and those that explain processes, in practice the same approach may be used in both contexts.

Visual and graphical methods are widely used to describe the pattern of diversity in communities. Often researchers simply want to plot a graph of the species abundance data and use the 
shape of this graph to draw conclusions about an assemblage. There are a number of methods of doing this and visual approaches to understanding species abundances have been widely used in the past and remain popular today (May, 1975; Magurran, 2004; McGill et al., 2007). One method that is frequently adopted is the rank abundance plot (MacArthur, 1957; Whittaker, 1960 and see Figure 1). The k-dominance plot (Lambshead et al., 1983) and Q statistic (Kempton \& Taylor, 1978) are alternative ways of presenting species abundance data (Magurran, 2004). McGill (McGill et al., 2007; McGill, 2011) argues that an empirical cumulative density function (eCDF) is a better method of presenting species abundance data (Fig. 2). This is because rank abundance plots are strongly influenced by species richness. Moreover, the eCDF approach is mathematically more powerful than the rank abundance plot (McGill, 2011).

Alternatively, the investigator can fit a known distribution to the data, or calculate metrics that can be used to evaluate an assemblage. For example, the log normal distribution which was first proposed by Preston (1948) and the log series distribution, which was introduced by Fisher (Fisher $e t$ al., 1943) provide a good fit to many natural communities. Diversity indexes linked to these models, such as Fisher's $\alpha$ statistic, are a convenient way of summarizing a community's diversity. Although inherently descriptive, it has been common practice to use these methods to make inferences about the processes that shape the patterns.

Biological models are the third method of approaching species abundance data. Here the key idea is to model the ecological processes that determine the relative abundance of species. Competition is usually regarded as the primary driver of this and so these models typically ask how niche space will be divided amongst competing species. The very first biological model was proposed by Motomura (1932). Later contributions include those by Sugihara (1989) and Tokeshi (1993; 1996). By definition these types of models are likely to be most relevant to small groups of species exploiting a common resource.

A fourth way of explaining inequalities in species abundances is to invoke neutral models. These models (e.g. Caswell, 1976; Bell, 2001; McGill, 2010) assume that biological differences between species play no role in shaping the pattern of abundance; in this they resemble the neutral theory of molecular genetics (Kimura, 1968). The model that has received the most attention is Hubbell's (2001) unified neutral theory of biogeography and biodiversity. Hubbell argues that species are functionally equivalent - at least as far as biodiversity is concerned - and that the pattern of species relative abundance in a local community is a result of both the species abundance distribution in the metacommunity (the source of colonists) and the extent of dispersal limitation (that is how isolated the local community is relative to the metacommunity). Because neutral models seek to expose the processes that shape species abundances, they differ from the classical null model approach in which a statistical test attempts to account for the influence of random chance (Gotelli \& McGill, 2006). Hubbell's model is called a unified model because it attempts to bring together patterns that historically have been treated separately, such as the species abundance distribution and the species area relationship, in a common framework. As McGill (2010) notes, there are six of these models, and although they are formulated in different ways, they make similar assumptions about nature. Specifically all six argue that individuals in the same species tend to be clumped, that species abundances across large scales such as a region are inequitable (some common and many rare species) and that spatial (and temporal) interactions between species are unimportant in explaining the diversity patterns that the models seek to explain.

These approaches have contributed many new insights into the pattern of biological diversity in ecological communities and the processes that shape this pattern. Nonetheless models based on contrasting and even mutually exclusive assumptions can generate predictions that match empirical data sets well (Chisholm \& Pacala, 2010). Thus, while a good fit between model predictions and 
observed data is essential, this in itself is not sufficient to prove that a particular model can account for the processes that underpin a species abundance distribution (Magurran, 2004; McGill et al., 2007; Connolly \& Dornelas, 2011; McGill, 2011). Stronger tests are needed (McGill et al., 2007).

There are a number of reasons why it has proved challenging to get a definitive explanation for the fundamental ecological pattern of commonness and rarity. As noted above, competing models can generate the same species abundance distribution, so fit alone is not enough to separate them. In addition, when models do make distinct predictions about abundance, this usually concerns the rare species (for example the log series distribution assumes a larger fraction of rare species than the log normal model does). However, it is the abundances of the rare species that are most vulnerable to sampling error (Preston, 1948). For example, any difference in catchability (Buckland et al., 2011) amongst species is likely to have the biggest impact on the detection of species that naturally occur at low frequencies. A related factor is that the extent of sampling in space, and its duration and frequency in time, influences our perception of the community structure (Loehle, 2006). When an assemblage is sampled repeatedly through time, the numbers of rare species encountered will increase (Magurran \& Henderson, 2003; McGill, 2003). Similarly, increasing the spatial extent of the sampling will change our view of how the assemblage is structured (May, 1975; Tokeshi, 1993, 1999; Magurran, 2011). The shape of the species area relationship is important here too (Tjørve, 2003; Tjørve \& Tjørve, 2008; Tjørve, 2009).

\section{WHERE FISH STUDIES CAN HELP}

Investigations of fish assemblages have the potential to increase our understanding of biological diversity, both through sharpened thinking on how communities are structured, and by providing data that will help tease apart the different explanations for patterns of commonness and rarity. Fishes are particularly useful subjects for exploring biodiversity patterns, as they live in habitats that range from temporary puddles (Costa \& Brasil, 1990) to vast oceans, can vary by many orders of magnitude in abundance and body size, and exhibit a wide range of life-histories and

behaviours. Because the taxon also includes many species that are commercially important, fisheries biologists routinely collect data that are invaluable for testing ideas. Here some of the insights that investigations of fish communities have delivered are explored, and the opportunities that such studies offer for improving our understanding of patterns of biological diversity in nature are discussed. Inevitably the focus is on the most familiar examples and case studies to the authors, but that should not detract from the central message, which is that investigations of fish communities have the potential to move this research field forward.

\section{WHAT IS MEANT BY A LOCAL COMMUNITY?}

One question that researchers and policy makers often ask concerns the number of species that are present in a particular locality or habitat. Ecologists who are trying to quantify the pattern of species abundances would also like to know how many species there are. Although the question seems straightforward, the answer rarely is. There are two issues here. The first is the difficulty of completely censusing the species present, the second the observation that all communities experience turnover. A new generation of statistics, developed by Anne Chao and colleagues, (Chao, 1987; Colwell \& Coddington, 1994; Chao et al., 2000; Gotelli \& Colwell, 2011) provide a means of estimating species richness and has proved a very useful technique (but see also Ugland et al., 2003; Ugland \& Gray, 2004; Ugland et al., 2005; Reichert et al., 2010). These methods draw on the frequencies or abundances of rarely sampled species to deduce the total number of species. The usual metaphor applied to this is that a local community resembles a sweet or candy jar; with sufficient sampling it should be possible to get an exact idea of how many species are present. However, the 
total number of taxa recorded in any natural system will continue to rise through time - even given perfect sampling - because new species colonize and existing ones become locally extinct (Fig. 3).

This constant inflow and loss of species is the idea that underpins MacArthur and Wilson's (1967) theory of island biogeography. The rate at which new species colonize will be related to how 'leaky' an assemblage is. Fish assemblages very nicely illustrate how leakiness varies. Thus, an isolated lake receives colonists only occasionally whereas a section of ocean will be open to a constant stream of new species. Indeed, fish assemblages can be viewed as distributed along a continuum of open to closed assemblages. This is an important resource to ecologists seeking to explain patterns of diversity. Variation in leakiness provides an opportunity to link changes in structure to the level of dispersal limitation - a key element of Hubbell's neutral theory. A classic example is the contrast in the structure of stream communities in Trinidad's Northern Range above barrier waterfalls, compared with equivalent streams in rivers that lack these barriers (Magurran, 2005) (Fig. 2). Another instance would be the lakes in Canada's Experimental Lakes Area (Beamish et al., 1976) as these vary in size and connectedness. There are many other possibilities. To date most tests of biodiversity models have used only a very limited number of datasets, with the tree communities in Barro Colorado Island (BCI) being one of the most thoroughly analysed (McGill, 2010). Any theory that seeks to offer general explanations for patterns of diversity needs to be demonstrably applicable to different community types, and it is here that fish communities have considerable and as yet barely exploited potential. Recent analyses have begun to explore the consequences of different types of dispersal. For example, Rosindell \& Cornell (2009) extend spatially explicit neutral models to include long-distance dispersal and test their predictions using the BCI data. The range of dispersal scenarios offered by fish communities could be invaluable to researchers working in this area.

There are other aspects of community ecology that are taking increasing note of dispersal limitation and the openness of assemblages. For instance, leakiness provides an opportunity to distinguish an established core community of species from the occasional or vagrant species that colonize and then become locally extinct. This concept - and its implications - are now explored.

\section{THE CORE COMMUNITY}

Within any local community some species are persistent - that is they occur repeatedly when the community is resampled through time - while others appear only occasionally. This pattern is evident at Hinkley Point - an estuarine fish assemblage in the U.K.'s Bristol Channel that has been sampled monthly for 30 years (Henderson, 2007; Henderson \& Bird, 2010). The tempo of the pattern will obviously be linked to the leakiness of the community with open ones receiving a stream of arriving species. In the Hinkley estuarine community species can be distinguished that are almost always present (the core species), from those that make occasional appearances (Fig. 4). This persistence is linked to abundance - core species are generally abundant, while occasional species are often rare. Importantly, this distinction is underlain by differences in the ecology of the species. Core species are typically those associated with estuarine habitats, while occasional species are often adapted to other environments, such as deep water or the open sea (Magurran \& Henderson, 2003). Moreover core species will be the ones responsible for much of the function (biomass production etc.). If the species abundance distribution at Hinkley Point is divided (based on data accumulated across three decades) into core and occasional species, abundances of core species resemble a log normal distribution, while the abundances of occasional species are more similar to a log series distribution. This finding is interesting because it shows that it makes biological sense to partition a species abundance distribution, and fit different models to the different parts. It also helps explain why some communities have an excess of rare species (Nee et al., 1991; McGill, 2003). Similar partitions have been applied to other communities, including insects (Ulrich \& Ollik, 2004; Ulrich \& 
Zalewski, 2006). Incidentally, the observation that there are subsets of species leads to interesting questions about what a local community actually is. Traditionally ecologists have considered communities to be groups of interacting species, though the extent of these interactions is probably a lot more limited than people often assume (Magurran \& Henderson, 2010; McGill, 2010). Assemblage is an alternative term that makes fewer assumptions about species interactions (Fauth et al., 1996).

\section{CURRENCIES OF ABUNDANCE}

Much of the literature on species abundance distributions treats abundance as synonymous with numbers of individuals. This is a practical decision since it is generally easier to count individuals than to measure biomass or energy. For communities of similar sized organisms, such as guilds of birds, it probably does not matter greatly. However, there is growing appreciation that examining how species abundance distributions are structured when abundance is measured in different currencies can help us understand the processes that shape diversity (Morlon et al., 2009). Indeed, some authorities (e.g. Tokeshi, 1993) argue that biomass is a much more informative measure of abundance if the goal is to test the veracity of niche partitioning models while other researchers have pointed out that different impressions community structure emerge when different measures are used (Saint-Germain et al., 2007). Since fish ecologists and fisheries scientists often measure both number of individuals and biomass, these data sets lend themselves well to establishing new perspectives in biodiversity research (Morlon et al., 2009).

An example of this is again provided by the Hinkley Point data [Figure 5(a)]. If log numerical abundance is plotted against log biomass the data will form a roughly triangular shape (Henderson \& Magurran, 2010). The boundaries of this triangle are determined by simple considerations. The left hand side represents the biomass (i.e. body size) of singleton species, the lower line is set by body size multiplied by abundance while the upper line represents the maximum total biomass for any species. Species are distributed within this triangle approximately at random; this pattern is consistent with the hypothesis that a community consists of a number of spatial guilds (Henderson \& Magurran, 2010). Spatial guilds are composed of species that use the structural habitat in a particular way (Lawton, 1990). Two examples of these in the Hinkley Point community are benthic species and open water fishes. Crucially, the species that make up these spatial guilds are distributed along axes that bisect the triangular space - and are visible because abundance is viewed in both currencies simultaneously (Henderson \& Magurran, 2010). Thus the community is composed of a number of spatial guilds, overlain one on the other. Temporal variation in abundance helps randomize the regular patterns of species with their spatial guilds. Now, because the distribution of species within the triangle approximates to random the shape of the triangle can be used to infer the form of the species abundance distribution in both currencies. (A regular distribution of species in biomass-numerical abundance space would also allow deduction of the shape of the species abundance distribution, but temporal variability in species abundances makes a strictly regular pattern unlikely). In many communities, such as Hinkley Point, the polygon represented by biomass-numerical abundance space will resemble an obtuse triangle. In such cases the distribution of biomass will be log normal in form, while the distribution of numerical abundance will be more similar to a truncated log normal (or log series) distribution (Henderson \& Magurran, 2010). This is exactly the pattern detected by Connolly et al. (2005) in their investigation of Pacific reef fishes and coral communities.

These observations allow predictions about communities. For example, if a group of organisms exploit a single spatial resource (such as fishes in a leaf litter bank) the distribution of species in biomass-numerical abundance space will fall around a single line, rather than in a triangle (Henderson \& Magurran, 2010). Another variant is illustrated by Malaysian stream fishes [Figure 5(b)]. Here the pattern resembles a roughly kite-shaped polygon. The sharp cut off point on the lower 
edge suggests that smaller fishes may not have been captured. In this instance both species abundance distributions (of biomass and numerical abundance) are roughly log normal [see Fig. 3 and Table 1 in Henderson \& Magurran (2010), for more discussion of these ideas].

A further application of this approach is that the likely consequences for community structure can be predicted of the removal of top predators, or of over-fishing of certain size classes, or of different sampling protocols. As long as the distribution of species in biomass-numerical abundance space is indeed approximately random - as is the case in the examples known to date - it can be seen how changes in the body size distribution will lead to changes in community structure.

\section{THE SIZE OF A COMMUNITY (EXPLAINING $S$ AND $N$ )}

A feature common to the various attempts to explain the shape of species abundance distributions is that researchers take the empirical values of $S$ (observed species richness) and $N$ (total numerical abundance - biomass can be used here too) and use these inputs to predict the relative abundance of $S$ species (McGill, 2010). One of the biggest unanswered questions in this research field (McGill, 2010) is what drives these values of $S$ and $N$. At the global level variation in species richness, for example along latitudinal gradients, is usually explored through correlations with factors such as productivity (Mittelbach et al., 2001). Environmental gradients, such as those of altitude and disturbance are also probed to explain variation in $S$. However, although $S$ and $N$ can be linked in interesting, though not always obvious, ways (May, 1975; Srivastava \& Lawton, 1998), $S$ and $N$ are rarely examined in tandem in such studies.

One way of thinking about this problem is to assume that communities have a capacity, that is that they can support a certain number of individuals (or biomass). This idea is similar to the notion of saturation, which suggests communities have a maximum size and all the available slots for individuals are occupied or saturated. Saturation is one of the assumptions of Hubbell's neutral model, but the extent to which ecological communities are saturated remains controversial. Nonetheless, communities that are not undergoing directional change (such as succession or disturbance) reveal that overall abundance is conserved through time (Fig. 6) even though the abundances of the individual species vary markedly. Indeed, the argument can be flipped around to show that community properties, such as total abundance or biomass, are preserved because the abundances of the individual species shift independently of one another (Magurran \& Henderson, 2010). As long as there are a reasonable number of species in the assemblage these changes will cancel one another out (Cottingham et al., 2001).

Dornelas et al. (2011) used Trinidadian fish communities to ask how total abundance varies across a species richness gradient. Total abundance was estimated in three ways: as numerical abundance, as biomass and as energy use. They found that, on average, each measure of total abundance increases with increasing species richness, but that the upper limit of abundance remains constant. This shows that the relationship between $S$ and $N$ is more predictable as $S$ increases. It also suggests that communities have a maximum size in terms of $N$ (and that this holds when abundance is measured in different ways) but that the patterns can be noisy, especially when $S$ is low. Another intriguing observation is that $N_{\max }$, that is the absolute abundance of the most abundant species, is independent of $S$. Once again this holds for each of the measures of abundance. There is another interesting implication of these results. Although the absolute abundance of $N_{\max }$ does not change across the gradient, the relative abundance of $N_{\max }$ declines as $S$ increases. The different behaviour of absolute and relative abundance measures is something that modelers of niche partitioning need to aware of, since they typically work with relative abundances. Taken together the results suggest that each community has a certain capacity. This capacity will be set by factors such as the amount of 
physical space, the types of physical space, primary productivity and so on. Community capacity constrains the upper limit on abundance $N$ as well as the number of species $S$. However, the exact number of species that do coexist in a community will be determined by processes such as dispersal limitation. Thinking about this in the context of Trinidad it can be seen how two rivers, which are similar in terms of physical structure and productivity, might support similar numbers of individuals, but vary in species richness because one of them was isolated by a barrier waterfall and receives fewer colonists. This is seen in Figure 2.

\section{FUTURE DIRECTIONS}

This review has highlighted just a few of the topics under the general heading of community structure that are readily explored using data from fish assemblages. In doing so the present study has tried to link pattern and process. The sheer diversity of fishes, and the large range of habitats in which they live make them an unusually interesting group in which to test these ideas. Furthermore, there are undoubtedly many untapped sources of data that have been produced by the types of routine sampling that fish biologists and ecologists undertake. There are numerous themes that could be productively explored in future work. These include tests that evaluate the role of biological differences between species in structuring local communities, and how these differences result in species being common or rare. Such tests might take advantage of the life history data that fish biologists routinely collect. It would also be interesting to ask how particular biological traits such as trophic position, mean body size, life form influence dispersal abilities (Drakare et al., 2006). The extent to which dispersal limitation influences community structure has already been mentioned but it would be instructive to explore the interaction between dispersal limitation and disturbance since isolated assemblages will receive fewer colonists to balance local extinctions. Species turnover is also important (Harte \& Kinzig, 1997; Arita \& Rodríguez, 2002; Tjørve \& Tjørve, 2008; Anderson et al., 2011) but has been barely touched on here. The geometry of species distribution patterns is another topic that is receiving a lot of attention in the ecological literature (e.g. Storch et al., 2008), but is one that may need to be approached in a different way when dealing with fish communities found in linear structures (such as river systems) or in isolated water bodies (such as lakes). Related to this are scaling issues. Various techniques for linking species occurrence to area now exist (e.g. Kunin, 1998; Ovaskainen \& Hanski, 2003). Most of these are focused on terrestrial systems, but a growing number of investigators of fish communities now explicitly include scale in their analyses (e.g. Chick et al., 2004; Higgins \& Strauss, 2008; Flinders et al., 2009; Kang et al., 2009; Strecker et al., 2011).

It is clear that fish studies have the potential to contribute to these and other fundamental ecological questions. But perhaps the biggest research gap that needs to be filled is how such investigations of the biological diversity of fish communities can help shape conservation policy at both local and regional scales.

\section{A CASE STUDY}

\section{FISH DIVERSITY AND CONSERVATION CHALLENGES IN THE ECOREGION OF THAILAND AND PENINSULAR MALAYSIA}

Thailand and west Malaysia are connected by a land bridge and have a total landmass of $>1$ $000000 \mathrm{~km}^{2}$. Thailand and the western part of peninsular Malaysia (western belt) are of Gondwanan origin (Rainboth, 1996; Yap, 2002) but the eastern region (eastern belt) is of Laurasian origin. Tectonic plates collided to create the landmass during the lower Mesozoic period (Rainboth, 1996). The area is topographically varied. Central and southwestern Thailand are relatively lowlying while 
there are mountain ranges in the west, north and eastern part of the country. In peninsular Malaysia, by contrast, mountain ranges run from north to south and divide the landmass into eastern and western coastal plains; these mountains are also the source of many streams and rivers. Subterranean streams and swamps add to the habitat diversity of this ecoregion but natural lakes are absent.

The ecoregion of Thailand and peninsular Malaysia forms part of the Indo-Burma and Sundaland biodiversity hotspot (Myers et al., 2000). The region is thought to have well over a thousand species of primary and secondary freshwater fishes (Yap, 2002) and its diversity has been recognised for years (Smith, 1945; Moshin \& Ambak, 1983; Rainboth, 1996). Fish surveys and collections, which began in the $19^{\text {th }}$ century, were initiated by ichthyologists such as G. Cuvier, A. Valenciennes, T. E. Cantor and P. Bleeker. To date, over 800 freshwater fish species have been recorded in Thailand (Salinee Khachonpisitsak unpublished data), and approximately 300 species (Lim \& Tan, 2002) in peninsular Malaysia. It is strongly believed that these figures are an underestimate not only because more than 10 new species or new records are being added to the list annually, but also due to observations by the authors which suggest that there are a substantial number of species yet to be discovered from this region. For instance, about 25 species out of 72 rare and endemic species detected in Thailand are yet to be formally described (Vidthayanon, 2005).

The challenges of documenting fish diversity in Thailand and peninsular Malaysia typify those often experienced in biodiverse but poorly studied regions. Paucity of research funding, combined with limited taxonomic expertise is one reason why freshwater fishes are not yet fully catalogued. However, high levels of uniqueness, endemicity and rarity is another. In Thailand, about $8.5 \%$ of freshwater fishes are endemic; the equivalent figure for peninsular Malaysia is about $10 \%$. Around $56 \%$ of the estimated 800 species in Thailand are unique species (species being restricted to a single watershed system) (Salinee Khachonpisitsak, unpublished data). Balitora, Homaloptera, Schistura (Balitoridae) and Akysis (Akysidae) are examples of genera that are consistently unique. On the other hand, just 22 species are widely distributed across the country with high abundance. These include representatives of genera such as Cyclocheilichthys, Puntius, and Osteochilus (Cyprinidae) (Howes, 1991). In peninsular Malaysia, an example of a fish found throughout the region is Poropuntius smedleyi (de Beaufort 1933) (Cyprinidae) while those with restricted ranges include Neolissochilus hendersoni (Herre 1940) (Cyprinidae), - reported on the island of Penang and Langkawi (Ahmad \& Lim, 2006) - and Clarias batu Lim \& Ng 1999 and C. sulcatus Ng 2004 (Clariidae). Furthermore, every survey of local communities uncovers some abundant and many rare species and thus confirms the universal pattern discussed elsewhere in this paper (Amir B. Ahmad, unpublished data).

There may never be a reliable species count for this ecoregion since habitat loss and habitat modification is occurring at a rate that makes it likely that a substantial fraction of fish species will be lost before they are formally identified. Peat swamp is one type of habitat in Peninsular Malaysia that has only relatively recently been recognised as having a rich fish fauna ( $\mathrm{Ng}$ et al., 1994). Unfortunately, large parts of the north Selangor peat swamp forest have been cleared to make way for agriculture and other human activities. This has changed the ground water hydrology and led to desiccation of the swamp forest, with the result that this unique habitat is now seriously threatened.

To date there have been few attempts to draw on the insights from analyses of species abundance distributions, and to apply these to the conservation of freshwater fish communities in biodiverse ecoregions such as Thailand and peninsular Malaysia. 


\section{CONSERVING BIOLOGICAL DIVERSITY}

Research into patterns of biological diversity in the natural world has been given new impetus by the growing concern about accelerating extinction rates and increased awareness of the important functions that this diversity contributes. Fishes are important targets of conservation, not just because they are economically and recreationally important, but also because they make up such a large fraction of the vertebrate diversity on Earth. However, much of the conservation effort to date has focused on what Bob May likes to call the furries and featheries (May, 2002); most species for which there are formal conservation assessments are mammals and birds. A striking example is that 62 out of the 81 one species recorded at Hinkley Point have not yet been evaluated against IUCN criteria.

Geographical isolation is the engine of diversification in fishes, as in other taxa. The remarkable diversity of freshwater species is therefore, to a large part, linked to the fragmentation of freshwater systems into many isolated drainages, lakes, and wetlands. However, because the water bodies involved can be limited in extent, many freshwater fish species have small populations and/or restricted ranges. Diversity - in freshwater fishes at least - is a natural corollary of rarity, and vice versa (Magurran, 2009).

The case study above described the challenges of quantifying patterns of biological diversity of freshwater fishes in a rich, but poorly studied ecoregion (Thailand and peninsular Malaysia). It shows there is often only a limited understanding of how many species are present, and what their distributional patterns are. Moreover, here - as in many other parts of the world - habitats are being lost before the fishes that live in them have been documented.

Although theories of biological diversity, such as the neutral model in its various forms, have been an intellectually exciting development in ecology, there is little evidence as yet that they have aided conservation managers (Clarke, 2009). There is nonetheless considerable potential for this to change (McGill \& Collins, 2003; McGill, 2010). The idea that local communities are embedded in a metacommunity is central to neutral theory and is also relevant to conservation policy in ecoregions such as Thailand and peninsular Malaysia. Many nature reserves conserve fragments of habitat but pay little attention to how the species involved are located in relation to their range. Theory tells us that it would be wise to take this into account as populations towards the edge of a species' range tend to be smaller than those in the middle (McGill \& Collins, 2003). Dispersal also needs to be considered. Analyses of fish communities also reveal that species abundances vary through time (Magurran \& Henderson, 2010) and show how important it is that conservation policy heeds this natural change (Mace et al., 2010). Finally, our investigations of local communities tell us that rarity and local extinction are natural phenomena (Magurran, 2009). By linking patterns at the local community level with the processes that shape those patterns conservation biologists will be able to develop management strategies that contribute the effective long term conservation of biological diversity.

AEM thanks Peter Henderson for his foresight in establishing and maintaining the Hinkley Point estuarine fish time series and for his generosity in sharing the data. She also acknowledges the European Research Council (BioTIME 250189) for funding. ABA thanks the Peninsular Malaysia Forestry Department, and the state forestry and fisheries departments for permission to conduct the fieldwork. ABA received financial and logistic support from University Malaysia Terengganu and he thanks Syed Ahmad Rizal, Wan Mohd Amzar and Mohamad Fahmi for assistance during sampling. SK is partially funded by a Royal Thai scholarship. Finally, the authors acknowledge the referees for their helpful comments on the paper. 
References

Ahmad, A. \& Lim, K. K. (2006). Inland fishes recorded from the Langawi Island, Peninsular Malaysia. Malayan Nature Journal 59, 103-120.

Alfred, E. R. (1969). The Malayan cyprinoid fishes of the family Homalopteridae. Zoologische Mededelingen 43, 213-237.

Anderson, M. J., Crist, T. O., Chase, J. M., Vellend, M., Inouye, B. D., Freestone, A. L., Sanders, N. J., Cornell, H. V., Comita, L. S. \& Davies, K. F. (2011). Navigating the multiple meanings of diversity: a roadmap for the practicing ecologist. Ecology Letters 14, 19-28.

Ardura, A., Linde, A. R., Moreira, J. C. \& Garcia-Vazquez, E. (2010). DNA barcoding for conservation and management of Amazonian commercial fish. Biological Conservation 143, 1438-1443.

Arita, H. T. \& Rodríguez, P. (2002). Geographic range, turnover rate and the scaling of species diversity. Ecography 25, 541-550.

Beamish, R. J., Blouw, L. M. \& McFarlane, G. A. (1976). A fish and chemical study of 109 lakes in the experimental lakes area (ELA), northwestern Ontaria, with appended reports on whitefish ageing errors and the northwestern Ontario baitfish industry. Technical Report Fish and Marine Services (Canada) n. 607.

Bell, G. (2001). Neutral macroecology. Science 293, 2412-2418.

Buckland, S. T., Studeny, A. C., Magurran, A. E. \& Newson, S. E. (2011). Biodiversity monitoring: the relevance of detectability. In Biological Diversity: Frontiers in Measurement and Assessment (Magurran, A. E. \& McGill, B. J., eds), pp. 25-36. Oxford: Oxford University Press.

Caswell, H. (1976). Community structure: a neutral model analysis. Ecological Monographs 46, $327-$ 354.

Chao, A. (1987). Estimating the population size for capture-recapture data with unequal catchability. Biometrics 43, 783-791.

Chao, A., Hwang, W.-H., Chen, Y.-C. \& Kuo, C. Y. (2000). Estimating the number of shared species in two communities. Statistica Sinica 10, 227-246.

Chick, J. H., Ruetz, C. R. \& Trexler, J. C. (2004). Spatial scale and abundance patterns of large fish communities in freshwater marshes of the Florida Everglades. Wetlands 24, 652-664.

Chisholm, R. A. \& Pacala, S. W. (2010). Niche and neutral models predict asymptotically equivalent species abundance distributions in high-diversity ecological communities. Proceedings of the National Academy of Sciences 107, 15821-15825.

Chivian, D., Brodie, E. L., Alm, E. J., Culley, D. E., Dehal, P. S., DeSantis, T. Z., Gihring, T. M., Lapidus, A., Lin, L.-H., Lowry, S. R., Moser, D. P., Richardson, P. M., Southam, G., Wanger, G., Pratt, L. M., Andersen, G. L., Hazen, T. C., Brockman, F. J., Arkin, A. P. \& Onstott, T. C. (2008). Environmental genomics reveals a single-species ecosystem deep within Earth. Science 322, 275-278.

Clarke, J. S. (2009). Beyond neutral science. Trends in Ecology and Evolution 24, 8-15.

Colwell, R. K. \& Coddington, J. A. (1994). Estimating terrestrial biodiversity through extrapolation. Philosophical Transactions of the Royal Society of London, B. 345, 101-118.

Connolly, S. R. \& Dornelas, M. (2011). Fitting and empirical evaluation of models for species abundance distributions. In Biological Diversity: Frontiers in Measurement and Assessment (Magurran, A. E. \& McGill, B. J., eds), pp. 123-140. Oxford: Oxford University Press.

Connolly, S. R., Hughes, T. P., Bellwood, D. R. \& Karlson, R. H. (2005). Community structure of corals and reef fishes at multiple scales. Science 309, 1363-1364.

Costa, W. J. E. M. \& Brasil, G. C. (1990). Description of two annual fishes of the genus Cynolebias (Cyprinodobtiformes: Rivulidae) from the Sao Francisco basin, Brazil. Ichthyological Exploration of Freshwaters 1, 15-22.

Cottingham, K. L., Brown, B. L. \& Lennon, J. T. (2001). Biodiversity may regulate the temporal variability of ecological systems. Ecology Letters 4, 72-85. 
Darwin, C. (1859). On the origin of species by means of natural selection, or the preservation of favoured races in the struggle for life. London: John Murray.

Dornelas, M., Phillip, D. A. T. \& Magurran, A. E. (2011). Abundance and dominance become less predictable as species richness decreases. Global Ecology and Biogeography in press (online early).

Drakare, S., Lennon, J. J. \& Hillebrand, H. (2006). The imprint of the geographical, evolutionary and ecological context on species-area relationships. Ecology Letters 9, 215-227.

Fauth, J. E., Bernardo, J., Camara, M., Resetarits, W. J., Van Buskirk, J. \& McCollim, S. A. (1996). Simplifying the jargon of community ecology: a conceptual approach. American Naturalist 147, 282-286.

Fisher, R. A., Corbet, A. S. \& Williams, C. B. (1943). The relation between the number of species and the number of individuals in a random sample of an animal population. Journal of Animal Ecology 12, 42-58.

Flinders, C. A., Ragsdale, R. L. \& Hall, T. J. (2009). Patterns of fish community structure in a long term watershed scale study to address the aquatic ecosystem effects of pulp and paper mill discharges in four us receiving streams. Integrated Environmental Assessment and Management 5, 219-233.

Gotelli, N. J. \& Colwell, R. K. (2011). Estimating species richness. In Biological Diversity: Frontiers in Measurement and Assessment (Magurran, A. E. \& McGill, B. J., eds). Oxford: Oxford University Press.

Gotelli, N. J. \& McGill, B. J. (2006). Null versus neutral models: what's the difference? Ecography 29, 793-800.

Harte, J. \& Kinzig, A. (1997). On the implications of species-area relationships for endemism, spatial turnover, and food web patterns. Oikos 80, 417-427.

Henderson, P. A. (2007). Discrete and continuous change in the fish community of the Bristol Channel in response to climate change. Journal of the Marine Biological Association, UK 87, 589-598.

Henderson, P. A. \& Bird, D. J. (2010). Fish and macro-crustacean communities and their dynamics in the Severn Estuary. Marine Pollution Bulletin 61, 100-114.

Henderson, P. A. \& Magurran, A. E. (2010). Linking species abundance distributions in numerical abundance and biomass through simple assumptions about community structure. Proceedings of the Royal Society London, B. 277, 1561-1570.

Higgins, C. L. \& Strauss, R. E. (2008). Modeling stream fish assemblages with niche apportionment models: patterns, processes, and scale dependence. Transactions of the American Fisheries Society 137, 696-706.

Howes, G. H. (1991). Systematics and biogeography: an overview. In Cyprinid Fishes: Systematics, Biology and Exploitation (Winfield, I. J. \& Nelson, J. S., eds). London: Chapman \& Hall.

Hubbell, S. P. (2001). The Unified Neutral Theory of Biodiversity and Biogeography. Princeton: Princeton University Press.

Kang, B., He, D., Perrett, L., Wang, H., Hu, W., Deng, W. \& Wu, Y. (2009). Fish and fisheries in the Upper Mekong: current assessment of the fish community, threats and conservation. Reviews in Fish Biology and Fisheries 19, 465-480.

Kempton, R. A. \& Taylor, L. R. (1978). The Q-statistic and the diversity of floras. Nature 275, 252253.

Kimura, M. (1968). Evolutionary rate at the molecular level. Nature 217.

Kottelat, M. (2005). Rasbora notura, a new species of cyprinid fish from the Malay Peninsula (Teleostei: Cyprinidae). Ichthyological Exploration of Freshwaters 16, 265-270.

Kottelat, M., Whitten, A. J., Karthikasari, S. N. \& Wirjoatmadjo, S. (1993). Freshwater Fishes of Western Indonesia and Sulawesi. Hong Kong: Periplus Editions.

Kunin, W. E. (1998). Extrapolating species abundance across spatial scales. Science 281, 1513-1515.

Lambshead, P. J. D., Platt, H. M. \& Shaw, K. M. (1983). The detection of differences among assemblages of marine benthic species based on an assessment of dominance and diversity. Journal of Natural History 17, 859-874. 
Lawton, J. H. (1990). Species richness and population dynamics of animal assemblages. Patterns in body size : abundance space. Philosophical Transactions of the Royal Society of London, B. 330, 283-291.

Lim, K. K. P. \& Tan, H. H. (2002). Freshwater fish diversty in Peninsula Malaysia: a review of recent findings. In Bringing Partnerships into Good Wetland Practices, pp. 3C 1-21. Universiti Sains Malaysia, Penang.

Loehle, C. (2006). Species abundance distributions result from body size - energetics relationships. Ecology Letters 87, 2221-2226.

MacArthur, R. H. (1957). On the relative abundance of bird species. Proceedings of the National Academy of Sciences 43, 293-295.

MacArthur, R. H. \& Wilson, E. O. (1967). The Theory of Island Biogeography. Princeton: Princeton University Press.

Mace, G. M., Collen, B., Fuler, R. A. \& Boakes, E. H. (2010). Population and geographic range dynamics: implications for conservation planning. Philosophical Transactions of the Royal Society of London, B. 365, 3743-3751.

Magurran, A. \& Henderson, P. (2010). Temporal turnover and the maintenance of diversity in ecological assemblages. Philosophical Transactions of the Royal Society of London, B. 365, 3611-3620.

Magurran, A. E. (2004). Measuring Biological Diversity. Oxford: Blackwell Science.

Magurran, A. E. (2005). Evolutionary ecology: the Trinidadian guppy. Oxford: Oxford University Press.

Magurran, A. E. (2009). Threats to freshwater fish. Science 325, 1215-1216.

Magurran, A. E. (2011). Measuring biological diversity in time (and space). In Biological diversity: frontiers in measuerment and assessment (Magurran, A. E. \& McGill, B. J., eds.), pp. 85-104. Oxford: Oxford University Press.

Magurran, A. E. \& Henderson, P. A. (2003). Explaining the excess of rare species in natural species abundance distributions. Nature 422, 714-716.

May, R. M. (1975). Patterns of species abundance and diversity. In Ecology and Evolution of Communities (Cody, M. L. \& Diamond, J. M., eds), pp. 81-120. Cambridge, MA: Harvard University Press.

May, R. M. (2002). The future of biological diversity in a crowded world. Current Science 82, 13251331.

McGill, B. (2003). Does Mother Nature really prefer rare species or are log-left-skewed SADs a sampling artefact? Ecology Letters 6, 766-733.

McGill, B. J. (2010). Towards a unification of unified theories of biodiversity. Ecology Letters 13, 627-642.

McGill, B. J. (2011). Species abundance distributions. In Biological Diversity: Frontiers in Measurement and Assessment (Magurran, A. E. \& McGill, B. J., eds), pp. 105-122. Oxford: Oxford University Press.

McGill, B. J. \& Collins, C. (2003). A unified theory for macroecology based on spatial patterns of abundance. Evolutionary Ecology Research 5, 469-492.

McGill, B. J., Etienne, R. S., Gray, J. S., Alonso, D., Anderson, M. J., Benecha, H. K., Dornelas, M., Enquist, B. J., Green, J. L., He, F., Hurlbert, A. H., Magurran, A. E., Marquet, P. A., Maurer, B. A., Ostling, A., Soykan, C. U., Ugland, K. I. \& White, E. P. (2007). Species abundance distributions: moving beyond single prediction theories to integration within an ecological framework. Ecology Letters 10, 995-1015.

Mittelbach, G. G., Steiner, C. F., Scheiner, S. M., Gross, K. L., Reynolds, H. L., Waide, R. B., Willig, M. R., Dodson, S. I. \& Gough, L. (2001). What is the observed relationship between species richness and productivity? Ecology 82, 2381-2396.

Morlon, H., White, E. P., Etienne, R. S., Green, J. L., Ostling, A., Alonso, D., Enquist, B. J., He, F., Hurlbert, A., Magurran, A. E., Maurer, B. A., McGill, B. J., Olff, H., Storch, D. \& Zillio, T. (2009). Taking species abundance distributions beyond individuals. Ecology Letters 12, 488501.

Moshin, A. K. M. \& Ambak, M. A. (1983). Freshwater Fishes of Peninsular Malaysia: Universiti Pertanian Malaysia. 
Motomura, I. (1932). On the statistical treatment of communities. Zoological Magazine, Tokyo (in Japanese) 44, 379-383.

Myers, N., Mittermeier, R. A., Mittermeier, C. G., da Fonseca, G. A. B. \& Kent, J. (2000). Biodiversity hotspots for conservation priorities. Nature 403, 853-858.

Nee, S., Harvey, P. H. \& May, R. M. (1991). Lifting the veil on abundance patterns. Proceedings of the Royal Society London, B. 243, 161-163.

Nelson, J. S. (1999). Editorial and introduction: the species concept in fish biology. Reviews in Fish Biology and Fisheries 9, 277-280.

Nelson, J. S. (2006). Fishes of the World, 4th edn. New York: Wiley.

Ng, H. H. \& Kottelat, M. (2000). A review of the genus Amblyceps (Osteichthyes: Amblycipitidae) in Indochina, with descriptions of five new species. Ichthyological Exploration of Freshwaters 11, 335-348.

Ng, H. H. \& Ng, P. K. L. (1998). A revision of the South-east Asian catfish genus Silurichthys. Journal of Fish Biology 52, 291-333.

Ng, P. K. L., Tay, J. B. \& Lim, K. K. P. (1994). Diversity and conservation of blackwater fishes in Peninsular Malaysia, particularly in the North Selangor peat swamp forest. Hydrobiologia 285, 203-218.

Ovaskainen, O. \& Hanski, I. (2003). The species-area relationship derived from species specific incidence functions. Ecology Letters 6, 903-909.

Preston, F. W. (1948). The commonness, and rarity, of species. Ecology 29, 254-283.

Rainboth, W. J. (1996). Fishes of the Cambodian Mekong. Rome: FAO.

Raunkaier, C. (1934). Life Forms and Statistical Plant Geography. Oxford: Oxford University Press.

Reichert, K., Ugland, K. I., Bartsch, I., Hortal, J., Bremner, J. \& Kraberg, A. (2010). Species richness estimation: Estimator performance and the influence of rare species. Limnology and Oceanography: Methods. 8, 294-303

Roberts, T. R. (1989). The freshwater fishes of Western Borneo (Kalimantan Barat, Indonesia). . Memoirs of the Californian Academy of Sciences 14, 1-210.

Rosindell, J. \& Cornell, S. J. (2009). Species-area curves, neutral models, and long-distance dispersal. Ecology 90, 1743-1750.

Saint-Germain, M., Buddle, C. M., Larrivée, M., Mercado, A., Motchula, T., Reichert, E., Sackett, T. E., Sylvain, Z. \& Webb, A. (2007). Should biomass be considered more frequently as a currency in terrestrial arthropod community analysis. Journal of Applied Ecology 44, 330339.

Smith, H. M. (1945). The freshwater fishes of Siam, or Thailand. Bulletin of the United States National Museum 188, 1-622.

Srivastava, D. S. \& Lawton, J. H. (1998). Why more productive sites have more species: an experimental test of theory using tree-hole communities. American Naturalist 152, 510-529.

Storch, D., Sizling, A. L., Reif, J., Polechová, J., Säizlingová, E. \& Gaston, K. J. (2008). The quest for a null model for macroecological patterns: geometry of species distributions at multiple spatial scales. Ecology Letters 11, 771-784.

Strecker, A. L., Casselman, J. M., Fortin, M. J., Jackson, D. A., Ridgway, M. S., Abrams, P. A. \& Shuter, B. J. (2011). A multi-scale comparison of trait linkages to environmental and spatial variables in fish communities across a large freshwater lake. Oecologia, 1-13.

Sugihara, G. (1989). How do species divide resources? American Naturalist 133, 770-787.

Tjørve, E. (2003). Shapes and functions of species-area curves: a review of possible models. Journal of Biogeography 30, 827-835.

Tjørve, E. (2009). Shapes and functions of speciesñarea curves (II): a review of new models and parameterizations. Journal of Biogeography 36, 1435-1445.

Tjørve, E. \& Tjørve, K. M. C. (2008). The species-area relationship, self-similarity, and the true meaning of the z-value. Ecology 89, 3528-3533.

Tokeshi, M. (1993). Species abundance patterns and community structure. Advances in Ecological Research 24, 112-186.

Tokeshi, M. (1996). Power fraction: a new explanation for species abundance patterns in species-rich assemblages. Oikos 75, 543-550. 
Tokeshi, M. (1999). Species Coexistence: Ecological and Evolutionary Perspectives. Oxford: Blackwell Science.

Ugland, K. I. \& Gray, J. S. (2004). Estimation of species richness: analysis of the methods developed by Chao and Karakassis. Marine Ecology Progress Series 284, 1-8.

Ugland, K. I., Gray, J. S. \& Ellingsen, K. E. (2003). The species-accumulation curve and estimation of species richness. Journal of Animal Ecology 72, 888-897.

Ugland, K. I., Gray, J. S. \& Lambshead, P. J. D. (2005). Species accumulation curves analysed by a class of null models discovered by Arrhenius. Oikos 108, 263-274.

Ulrich, W. \& Ollik, M. (2004). Frequent and ocasional species and the shape of relative-abundance distributions. Diversity and Distributions 10, 263-269.

Ulrich, W. \& Zalewski, M. (2006). Abundance and co-occurrence patterns of core and satellite species of ground beetles on small lake islands. Oikos 114, 338-348.

Vidthayanon, C. (2005). Thailand Red Data: Fishes. Bangkok: Office of Natural Resources and Environmental Policy and Planning.

Ward, R. D., Hanner, R. \& Hebert, P. D. N. (2009). The campaign to DNA barcode all fishes, FISHBOL. Journal of Fish Biology 74, 329-356.

Watt, A. S. (1947). Pattern and process in the plant community. Journal of Ecology 35, 1-22.

Whittaker, R. H. (1960). Vegetation of the Siskiyou Mountains, Oregon and California. Ecological Monographs 30, 279-338.

Yap, S. Y. (2002). On the distributional patterns of Southeast Aisan freshwater fish and their history. Journal of Biogeography 29, 1187-1199.

Zemlak, T. S., Ward, R. D., Connell, A. D., Holmes, B. H. \& Hebert, P. D. N. (2009). DNA barcoding reveals overlooked marine fishes. Molecular Ecology Resources 9, 237-242. 
Figure 1

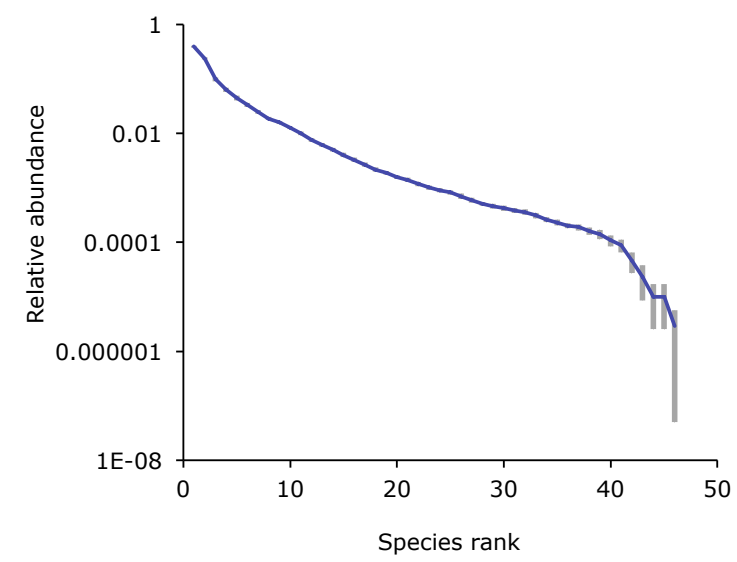

Figure 1. Ecological communities typically have some common and many rare species. This graph illustrates the relative abundances of species in the Hinkley Point (Bristol Channel, UK) estuarine community of fish, that has been surveyed for three decades (see Henderson, 2007; Henderson \& Bird, 2010 for the methodology used to sample fish at Hinkley Point). The rank abundance plot summarises the pattern across the time series. Values for first ranked species disregarding species identity, second ranked species, third ranked species and so one, have been averaged for each year the time series. Grey bars show the $95 \%$ confidence limits around these mean values. The graph has been re-drawn from Magurran \& Henderson (2010). 
(a)

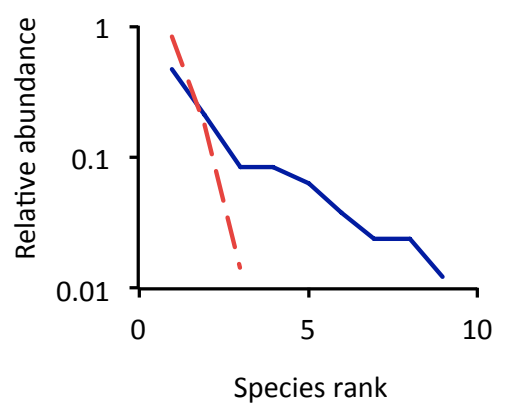

(b)

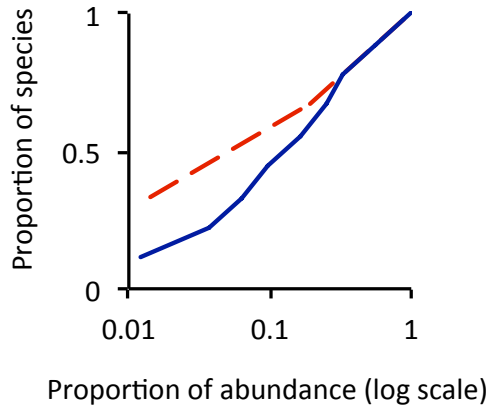

Figure 2. (a) Rank abundance plots are a traditional method of illustrating species abundance data. Here the graph contrasts the pattern of fish diversity seen in two localities in Trinidad's Northern Range. One site (Upper Aripo) - labelled 'barrier' - is upstream of a barrier waterfall and thus experiences a high level of dispersal limitation. The other (Upper Tacarigua) - labelled 'no barrier' is in a river that is similar in terms of size and elevation but where there is no barrier waterfall. The site above the barrier has fewer species, and the pattern on the rank abundance graph suggests that this is a very uneven community with one species dominating. However, the impression of evenness is confounded by the differences in species richness. In (b) the data are replotted in the form of an eCDF (empirical cumulative distribution function). Here the species are sorted from least to most abundant. The cumulative abundances are then calculated and plotted (using a log scale) on the x-axis. The yaxis standardizes species richness (by dividing each species rank by total richness) and plots the values $1 / S$ to 1 . This standardization makes it possible to directly compare assemblages that differ in species richness. In this example this method of plotting shows that the barrier site has a higher proportion of rare species relative to its richness. This is evident from the fact that the line for the 'barrier' assemblage lies above that of the 'no barrier' assemblage at the left hand (rare) side of the graph (AEM unpublished data). 
Figure 3

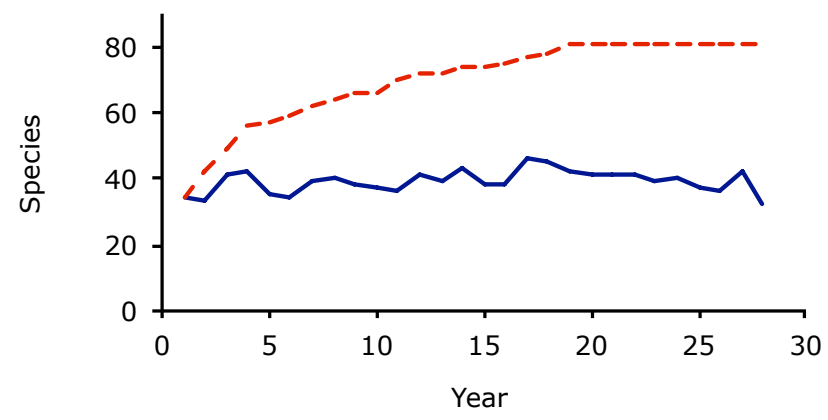

Figure 3. The lower (solid) line shows the number of species caught each year at Hinkley Point estuarine assemblage (Bristol Channel, UK - a in Figure 1), while the upper (dashed) line indicates the cumulative number of species through the three decade time series. 
Figure 4

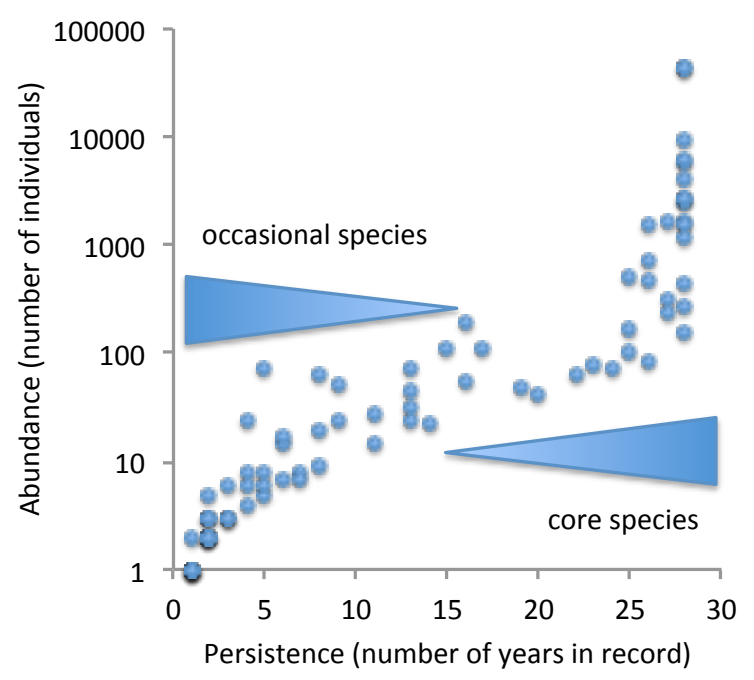

Figure 4. Species that are more persistent in the record are also more abundant. This graph plots the numerical abundance of species in the Hinkley Point estuarine assemblage (Bristol Channel, UK), against number of years the species is present. Persistent species are regarded as core species, infrequent species as occasional ones. There are ecological differences between the two sets of fish, with the persistent ones typically more adapted to estuarine habitats. This conclusion is not greatly affected by the position of the separation point. See Magurran \& Henderson (2003) for more details. 

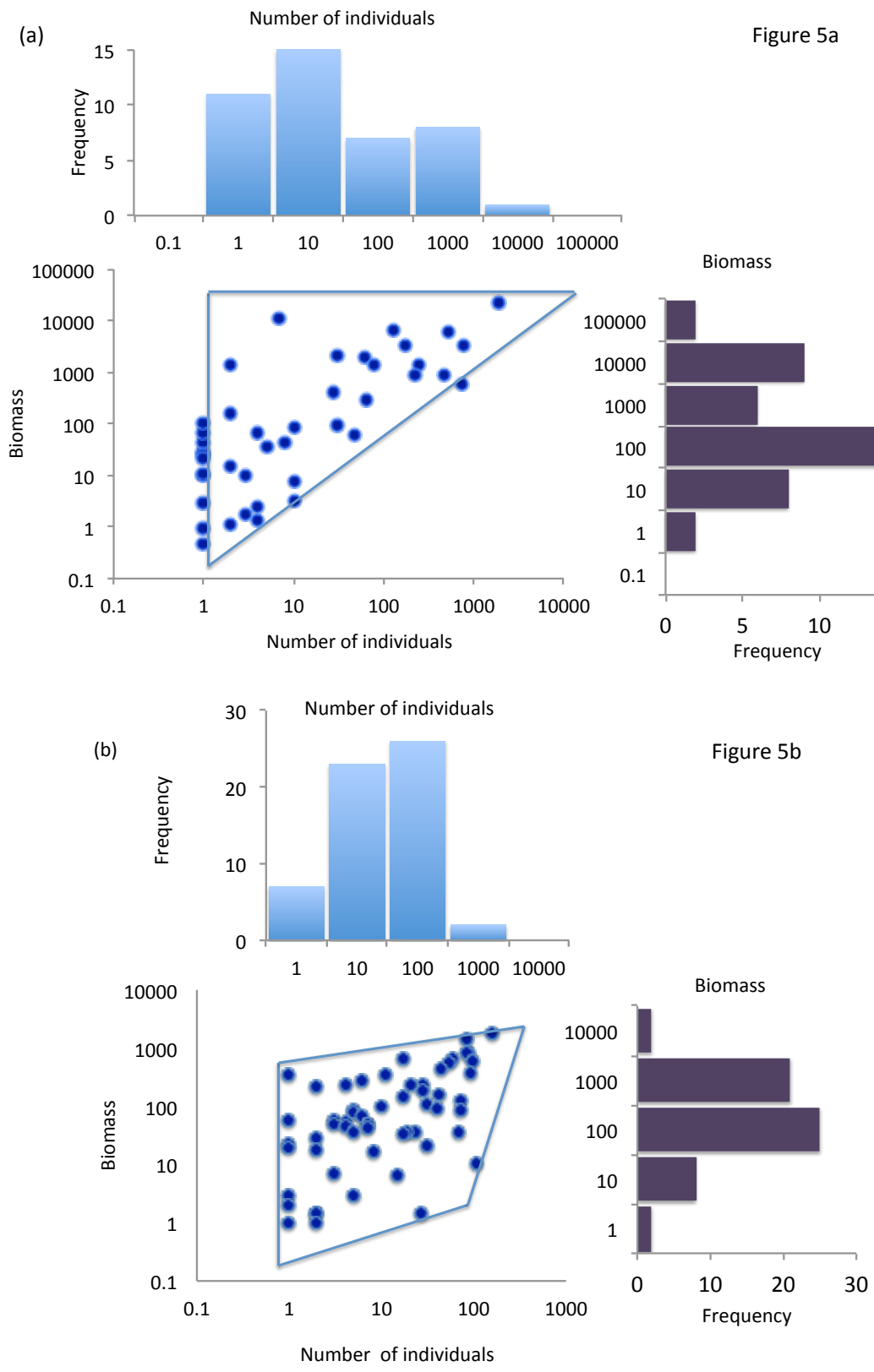

Figure 5. The relationship between biomass and numerical abundance (number of individuals) in two fish communities. These graphs show how the species abundance distributions of biomass and numerical abundance are related to this relationship. Indeed the shapes of these species abundance distributions can be deduced from the bounded area (usually triangular in shape) within which the points fall, as long as the distribution of species within this area is approximately random (an assertion supported by empirical data and grounded in the theory of spatial guilds - see Henderson \& Magurran (2010)). In the case of (a) - where the Hinkley Point estuarine assemblage was sampled over 12 months in 2008, the pattern resembles an obtuse triangle - probably the most common configuration. The biomass species abundance distribution resembles a log normal, while the species abundance distribution based on numbers of individuals has an excess of rare species. In contrast in (b) - Malaysian stream communities of fishes - the polygon has a sharp cut off point at the lower edge and forms a roughly kite-shaped polygon. This pattern can occur when very small individuals are not included in a sample (for example if the mesh size of a seine net allows the smaller fishes through) and was predicted by Henderson \& Magurran (2010) - [see their Fig. 3(d)]. Figure 3b is based on data from nine small streams in Peninsular Malaysia. Fish samples were obtained using a battery-powered backpack electroshocker (Smith-Root model LR-25). Sampling reaches were 
blocked using stop-nets at both ends to prevent fishes from entering or escaping the site. Fishes were collected by moving upstream and carefully sampling all microhabitats present within the reach (Henderson \& Magurran, 2010). To minimize mortality, all captured fishes were placed in collapsible loop-nets and immersed in flowing water. Small fishes were placed in a bucket separately. All fishes were identified to species in the field, counted, measured for total and standard length and weighed before being released at the end of each sampling. Any unidentified species were preserved in $10 \%$ formalin in the field and were left in fixative for 2 weeks. These were later soaked in the tap water to remove excessive formalin for further identification before transferring the specimens into $70 \%$ ethanol for long-term preservation. All specimens were classified and identified using relevant taxonomic keys (Alfred, 1969; Roberts, 1989; Kottelat et al., 1993; Rainboth, 1996; Ng \& Ng, 1998; Ng \& Kottelat, 2000; Kottelat, 2005).

(a)

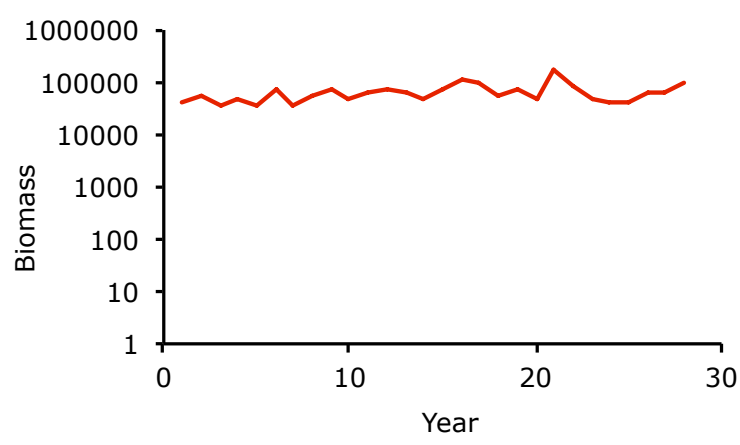

(b)

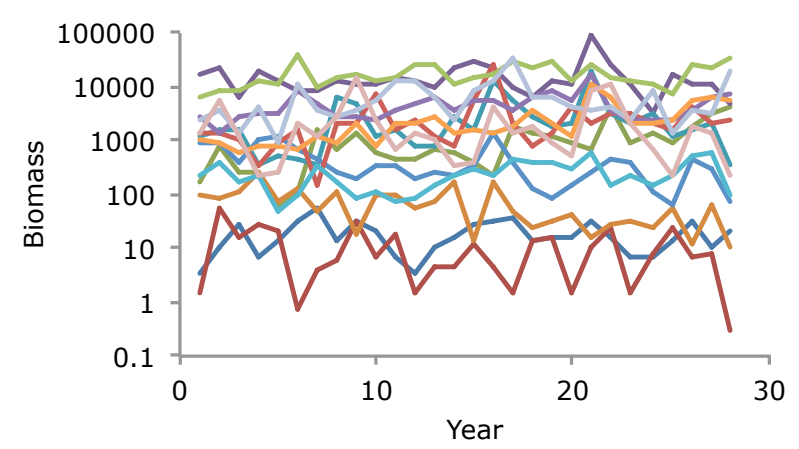

Figure 6

Figure 6. Temporal trends in the abundance of the fish community at Hinkley Point. (a) Overall biomass (g) through a three decade time series. (b) Year to year variation in the abundance of species (biomass (g)) that are always present. See Magurran \& Henderson (2010) for more details and further discussion of the patterns. 